\title{
Cost effectiveness analysis of total laparoscopic hysterectomy versus total abdominal hysterectomy for uterine fibroids in Western China: a societal perspective
}

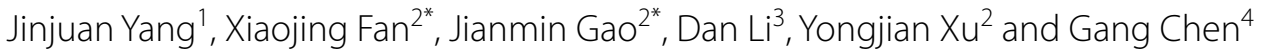

\begin{abstract}
Background: As a common female pelvic tumor, uterine fibroids remain the leading cause for hysterectomy in China. Hysterectomy provides a good surgical treatment of uterine fibroids, and it guarantees the removal of all uterine fibroids without lower risk of recurrence. This study compares the cost effectiveness of total laparoscopic hysterectomy (TLH) versus total abdominal hysterectomy (TAH) for women with uterine fibroids from a societal perspective.

Methods: An economic analysis was conducted in 392 patients (TLH $n=75 ; \mathrm{TAH} n=317$ ), including all relevant costs over a 12-month time horizon. Primary outcome was major surgical complications; secondary outcomes were postoperative discomfort symptoms and time of return to normal activities. Clinical, outcomes and costs data were collected from medical records, telephone survey and financial information system. Generalized linear models were used to assess costs and outcomes differences between the two groups. Incremental cost effectiveness ratio (ICER) was used to estimate the cost effectiveness.
\end{abstract}

Results: Mean direct costs were $\$ 2,925.71$ for TLH, $\$ 2,436.24$ for TAH, respectively. Mean indirect costs were $\$ 1,133.22$ for TLH, \$1,394.85 for TAH, respectively. Incremental societal costs were $\$ 256.86$ (95\%Cl: 249.03-264.69). Mean differences in outcome were: $4.53 \%$ (95\%Cl: $4.35-4.71)$ for major surgical complications; $6.75 \%$ (95\%Cl: 6.45-7.05) for postoperative discomfort symptoms; 1.27 (95\%Cl: 1.23-1.30) weeks for time to return to normal activities. ICER of TLH was \$5,669.16 (95\%Cl: 5,384.76-5,955.56) per complication averted, $\$ 3,801.54$ (95\%Cl: 3,634.81-3,968.28) per postoperative discomfort symptoms averted and \$202.96 (95\%Cl: 194.97-210.95) per week saved to return to normal activities.

Conclusions: TLH is cost effective compared with TAH in preventing additional complications based on our estimated conservative threshold in China. The findings provide useful information for researchers to conduct further cost effectiveness analysis based on prospective study which can provide stronger and more evidence, in China. In addition, the data may be useful for Chinese health care policy-makers and medical insurance payers to make related health care decisions.

Keywords: Uterine fibroids, Incremental cost effectiveness ratio, Total laparoscopic hysterectomy, Total abdominal hysterectomy

*Correspondence: fanxj112@xjtu.edu.cn; gaojm@mail.xjtu.edu.cn

${ }^{2}$ School of Public Policy and Administration, Xi'an Jiaotong University,

Xi'an 710049, People's Republic of China

Full list of author information is available at the end of the article

\section{Introduction}

Uterine fibroids are the most common female pelvic tumor, causing lots of health risks of women [1-3]. It is reported that $60 \%$ of women of reproductive age 
are attacked with uterine fibroids, and $80 \%$ of women develop the disease during their lifetime [4]. While most fibroids are asymptomatic, they are clinically apparent in up to $30-40 \%$ of women aged 40 and older and up to $25 \%$ of women of all ages $[1,5]$. Hysterectomy provides a good surgical treatment of uterine fibroids, and it guarantees the removal of all uterine fibroids without lower risk of recurrence [6]. Hysterectomy has been the major surgical treatment of uterine fibroids, approximately $75 \%$ of all fibroid treatments [3, 4]. Hysterectomy is the most common nonpregnancy-related gynecologic surgical procedure performed worldwide, with rates of 3.62 per 1,000 women in Germany [7], 3.12 per 1,000 women in Australia [8], 5.1 per 1,000 in 2004 in the United States and 17 per 1,000 women in India [9] and uterine fibroids are the leading cause of hysterectomy $[10,11]$. In the United States, it is estimated that annual direct costs of hysterectomy were $\$ 0.78$ to $\$ 3.5$ billion and lost work costs ranged from $\$ 0.55$ to $\$ 9.35$ billion annually [12]. Health care expenses and related indirect costs, such as the losses of monetary income due to disability and time out of work, cause a significant societal and economic burden. However, there is a lack of information on the incidence of uterine leiomyoma with national database in China. Gu et al. reported that 147,966 patients with leiomyomas were performed by hysterectomy in hospitals (excluding military hospitals) in mainland China in 2010 [13].

To date, various hysterectomy procedures with minimized invasiveness have been developed [14-21]. The main approaches for hysterectomies are abdominal, vaginal, laparoscopic, and robotic assistance [22]. Extensive studies compared the advantages of various hysterectomies. Most studies have shown that laparoscopic hysterectomy requires smaller incisions, less intraoperative blood loss, shorter length-of-hospital stay (LOS), faster recovery, better short-term quality of life (QOL) and quicker return to activity in daily life or work, as compared with abdominal hysterectomy or vaginal hysterectomy [23-27]. However, according to a multicentre randomised trial that evaluated the outcomes and cost effectiveness of abdominal hysterectomy, vaginal hysterectomy and laparoscopic hysterectomy, the results showed that laparoscopic hysterectomy was associated with a significantly higher rate of major complications and required longer operative times [28]. Aarts et al. evaluated 47 randomised controlled trials and found that laparoscopic hysterectomy had a greater risk of urinary tract injury [22].

Cost effectiveness analysis can provide an important tool in determining which procedure is cost effective for patients, payers and policy makers. Findings on the cost effectiveness of various hysterectomies are controversial.
Rutstein et al. reported that laparoscopic hysterectomy was cost effective compared with abdominal hysterectomy or vaginal hysterectomy, when considering total direct hospital costs, complications, and morbidity [29]. Graves et al. found that TLH was cost effective procedure compared to $\mathrm{TAH}$, for early endometrial cancer, when measured by quality-adjusted life years (QALYs) [30]. On the other hand, Sculpher et al. compared one-year costs and QALYs of abdominal hysterectomy, vaginal hysterectomy and laparoscopic hysterectomy [31] and Garry et al. performed a multicentre randomised trial comparing abdominal hysterectomy, vaginal hysterectomy and laparoscopic hysterectomy [28]. Both studies found that the cost effectiveness of laparoscopic hysterectomy in the comparison with abdominal hysterectomy is finely balanced, and laparoscopic hysterectomy was not cost effective compared to vaginal hysterectomy. However, both studies estimated the costs of different hysterectomies from a health service perspective, and did not analyze the productivity savings in monetary terms. When the productivity losses of patients and caregivers were considered, laparoscopic-assisted vaginal hysterectomy is found to be the most cost-effective procedure [23].

Due to disparities in demographic factors, economic, medical level and health care system, a diversity of costs associated with hysterectomy was found among several countries [27] even among various regions in the United States [32]. Previous research in mainland China compared the clinical effects of different hysterectomies $[20,33-37]$, or the costs during the hospitalization [13, 38,39 ]. There is a relative absence of data on social costs including healthcare costs and productivity losses in mainland China. To date, few studies have performed a cost effectiveness analysis of various hysterectomy procedures in China, from a societal perspective. To our best knowledge, only Leng et al. compared costs, health care utilization and QOL of TAH, laparoscopic hysterectomy and $\mathrm{TVH}$, but they made the comparison only in a short 28-day time horizon [38]. A longer, broader, societal perspective is therefore needed to estimate the cost effectiveness of different hysterectomy procedures in mainland China. Therefore, our study aims to evaluate the cost effectiveness of TLH versus TAH for women with uterine fibroids in Western China, from a societal perspective, over a 12-month time horizon.

\section{Methods}

Data

A retrospective observational study was performed of patients who underwent total hysterectomy for uterine fibroids by TAH and TLH, between January 1, 2011 and December 31, 2012, at the First Affiliated Hospital of Xi'an Jiaotong University (FHXJTU). Patients received 
surgical treatment according to an International Classification of Diseases, ninth revision, Clinical Modification codes: 68.401 for TAH and 68.405 for TLH, at FHXJTU, during 2011 to 2012. All the operating surgeons had more than 10-year of experience as gynaecologists, and laparoscopic surgeons were well-trained and experienced. Patients included were diagnosed with uterine fibroids. We excluded patients with histologic evidence for malignancy or patients with other benign gynaecologic diseases. During the study period, two patients with uterine fibroids chose TVH. Rather, the majority of TVH patients had the procedure because of a uterine prolapse. The indication for TAH or TLH was: a) symptomatic uterine fibroids, including heavy menstrual bleeding, pelvic pressure and pain; $b$ ) no desire to bear children, and c) the patient's personal preference and beliefs or attitudes towards TAH or TLH. There were no significant differences in the indications between the two procedures, $\mathrm{TAH}$ and TLH. The study compared two procedures of TAH and TLH. The final study sample $(n=392)$ was composed of 317 patients who underwent TAH and 75 patients who underwent TLH. The flowchart on the sample selecting process of this study is shown in Fig. 1.

\section{Measurement \\ Socio-demographic and clinical characteristics}

Socio-demographic characteristics include each patient's age, insurance status, employment status and living location. The clinical characteristics includes body mass index (BMI), number of births, previous delivery, menopause, type and size of fibroid, previous abdominal operation, contraceptive ring, disease severity on admission, and comorbidity. Comorbidities includes hypertension, diabetes, anemia, respiratory tract infection, asthma, hepatitis, ovarian cyst, cervicitis, pelvic inflammatory disease, bladder distention, uterine prolapse, hyperthyroidism, hypothyroidism, congenital heart disease. Surgical procedures data includes type of anaesthesia, time in

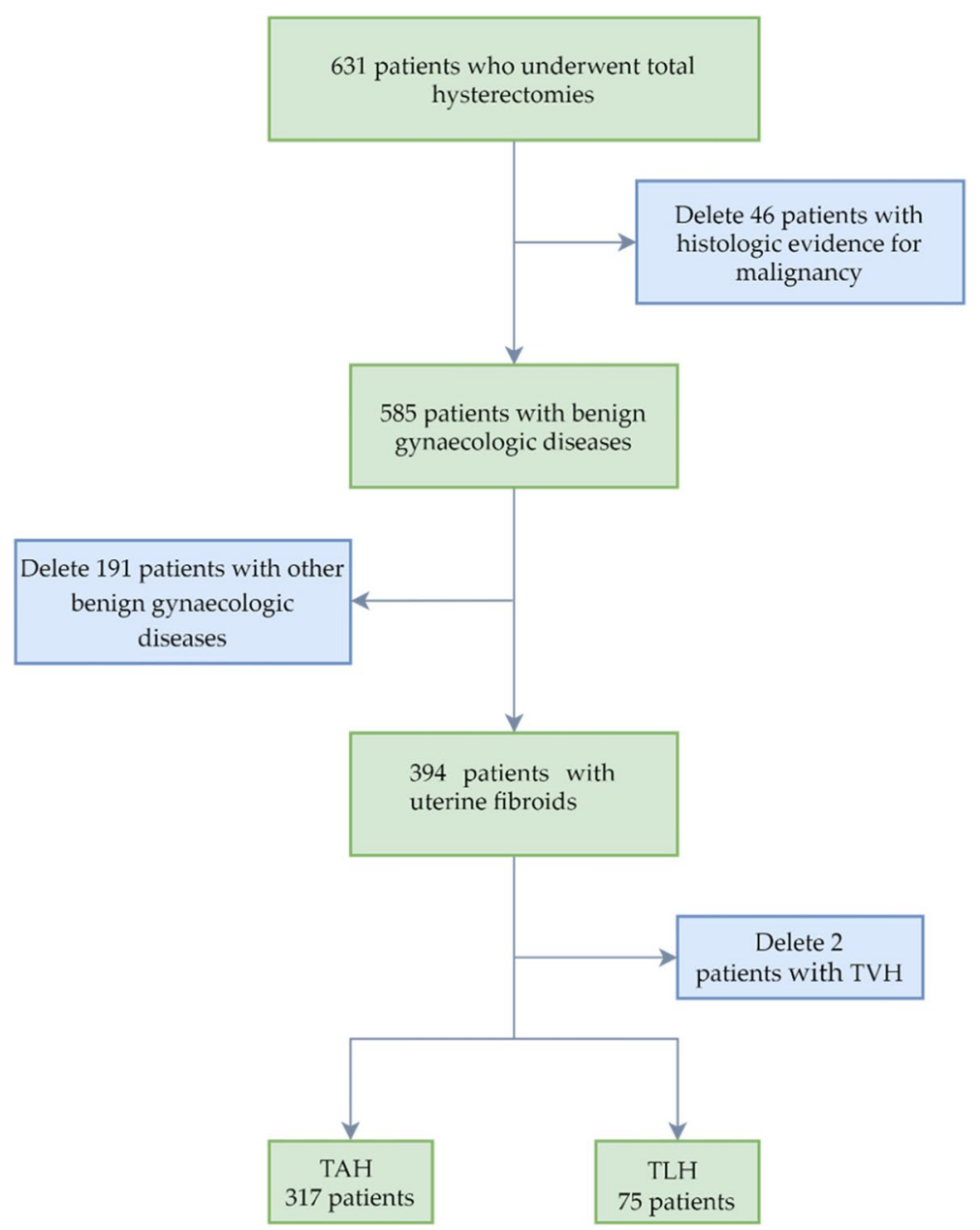

Fig. 1 Flowchart on the sample selecting process of this study. 
operating room, estimated blood loss (EBL) during surgery, received blood transfusion, secondary procedures, uterine volume. Other clinical data includes antibiotic usage, rate of major surgical complications, pre-operative and post-operative length of stay (LOS) and discomfort symptoms. Socio-demographic and clinical characteristics were collected from the patients' medical records.

\section{Effectiveness}

The primary measure of effectiveness was major surgical complications, which include both intraoperative complications and postoperative complications. Intraoperative complications were defined as ureteral injury, bladder injury, or EBL of more than 1,000 ml. Postoperative complications were defined as fever which was defined as an oral temperature of $38{ }^{\circ} \mathrm{C}$ or greater, on two successive occasions $4 \mathrm{~h}$ apart, excluding the first 24 operative hours [40], incision dehiscence, secondary suture, intestinal obstruction and hospitalization of more than 30 days. Period of hospitalization was chosen rather than 30-day readmission because no study patient was readmitted to a hospital within 30 days [26, 30, 41].

Rate of discomfort symptoms, time of return to normal activity (defined as able to perform most activities at $90 \%$ of preoperative levels), were used as secondary measures of effectiveness. After the hysterectomy, discomfort symptoms include wound pains, vaginal pains, gas pains, bowel symptoms, bloating, red vaginal bleeding, trouble passing urine or stool, granulation tissue, etc. Outcome data of measures of effectiveness were obtained from the patients' medical records and from interviews with the patients during their postoperative visits or by telephone survey.

\section{Costs}

To evaluate the economic consequences of two procedures from a societal perspective, we assessed the direct costs (including direct medical costs and direct nonmedical costs), and productivity losses of both patients and caregivers [42]. Direct medical costs refer to all medical expenses incurred during the hospitalization, surgery, drugs (both western and traditional Chinese medicine), treatment, investigations (e.g., X-ray, CT, electrocardiogram, blood tests, et al.), nursing care, consultations, blood transfusions and ward stay. We define the medical cost as the payments by the patient and insurance scheme. Direct non-medical costs refer to the patient's transportation costs when travelling to the hospital. Indirect costs refer to the value of the productivity losses by both the patients and the caregivers after the operation. Indirect costs in this study were calculated by multiplying the number of weeks absent from work by the patient's estimated weekly wage rate. In the case of retired or nonworking patients, costs of productivity loss could not be assessed using this method. However, it is incorrect to neglect the value of reduced time for leisure activities, and unpaid work (e.g., housekeeping, voluntary community work) [43]. In terms of methodology how to value the loss of time of retired and nonworking patients, some published studies used a proxy good method to value the reduction of time of unpaid services, leisure activities, and voluntary community work, by using equivalent market price for unpaid productivity (i.e., market wage rate of a housekeeper) $[44,45]$. Therefore, indirect costs for those retired and unemployed patients, we calculated by multiplying the weeks to normal activity with the market wage rate of housekeeping (i.e., $\$ 56.6$ per week in 2011) [46]. A sensitivity analysis with a range of $\pm 20 \%$ of the market wage rate of a housekeeper, was performed to estimate productivity losses of retired and nonworking patients. All costs were adjusted for inflation to 2020 values using 3\% discount rate and reported in 2020 U.S. dollars ( $\$ 1=¥ 6.900)$ [47]. Medical costs data was collected from the financial information system of FHXJTU, whilst direct non-medical costs and indirect costs data were collected through interviews with the patients during their postoperative visits or by telephone survey over a 12-month period.

\section{Cost effectiveness analysis}

The ICER was used to estimate the cost effectiveness of TLH versus TAH for women with uterine fibroids. The ICER was calculated as the incremental cost between $\mathrm{TLH}$ and TAH, divided by the difference in their effect.

Multi-variable adjustments of cost and effect were performed using general liner models (GLM) to adjust for the potential differences on preoperative socio-demographic and clinical characteristics between two patient groups. GLM with a log-link function and gamma distribution, was used to adjust the costs, LOS and time to normal actives, whilst rate of major surgical complications and rate of discomfort symptoms, were adjusted by GLM with a logit-link function and binomial distribution. Bootstrapping on patients' adjusted costs and effects across 1,000 replicates was performed to allow for robust assessment of uncertainty of costs, effects and cost effectiveness. Ninety-five percent confident intervals (95\% CIs) were calculated for the ICERs using these replicates.

To date, there is no universally accepted threshold of the acceptable cost for the effect measures used as major surgical complications. When the outcome measure is preference-based utility score and the ICER is expressed as cost per QALY gain or cost per disability-adjusted life-year avoided, the World Health Organization has suggested a cost effectiveness threshold of three times the national annual gross domestic product (GDP) per 
capita [48]. A previous systematic review suggested an acceptable ICER would not exceed a conservative threshold of US $\$ 20,000$ per the reduction of one additional major complication [24]. The $\$ 20,000$ figure was one half of the threshold of cost per QALY adopted by the National Institute for Health and Care Excellence in the UK at that time. According to this method, a threshold of cost to prevent one additional complication is about one and a half times the local GDP per capita. Considering the GDP per capita in China was US\$5,618 in 2011 (inflated to 2020, \$7,033) [49] we estimate the threshold of cost to prevent one additional complication to be $\$ 10,995$ in our study.

\section{Ethics statement}

Ethics approval and consent for the study was approved by the Ethics Committee of the Xi'an Jiaotong University Health Science Center (approval date: 30/6/2014). Prior to the telephone interview, verbal consent was obtained from all subjects involved in the study. All patient information was anonymised and deidentified prior to analysis.

\section{Statistical analysis}

For the normally distributed continuous variables, analysis of variance (ANOVA) or t test was used, whilst for categorical data, chi-squared tests or Fisher exact tests were conducted to study statistical significance between the two patient groups. Non-normally distributed variables (based on the Shapiro-Wilk test) were reported as the median with the interquartiles (i.e., Q1-Q3) or mean \pm the standard deviation (e.g. LOS and costs of distinct surgical types) and were compared by using the nonparametric Mann-Whitney U test.

The multiple imputation by chained equations (MICE) method [50] was used to deal with missing data in three variables-days back to normal activity $(n=89)$, days back to work $(n=89)$, and discomfort symptoms $(n=89)$. Data were missing in 89 cases (TAH: 73, TLH: 16), out of 392 included patients (TAH: 317, TLH: 75). There was no significant difference in rate of missing values between the two groups $(p>0.05)$. The imputation procedure used an iterative Markov chain Monte Carlo (MCMC) method based on multivariate normal or logistic regression [50] and involved replacing each missing value in the dataset with 20 plausible values that presented the uncertainty. The 20 resultant multiple imputed datasets were then analysed using standard complete-case procedures and the results were then combined using Rubin rules [51].

All statistical tests were 2 -sided. $P$ value less than 0.05 was considered statistically significant. Analyses were performed using the Stata version 12.0 (StataCorp
LP, College Station, Texas, USA) and Microsoft Access (Microsoft Corporation, Redmond, Wash).

\section{Results}

Patients' socio-demographic and clinical characteristics are summarized in Table 1 . Mean \pm standard deviation (SD) age were $45.88 \pm 4.13$ years and $45.29 \pm 4.48$ years for the TLH and TAH patient groups, respectively. Most characteristics of patients are comparable between the two groups. There were no significant differences between the two groups in age, BMI, number of births, previous delivery, menopause, size of fibroid, previous abdominal operation history, whether they used a contraceptive ring, severity on admission, comorbidities, insurance status, employment status or living location (all $p>0.05$ ). Patients in the TLH group were significantly more likely to have a single fibroid than multiple fibroids, compared to patients in the TAH group $(p=0.002)$.

Table 2 presents the surgical (including both intraoperative and postoperative) characteristics and clinical outcomes. There were significant differences between the two surgical groups with respect to the time spent in the operating room (time in OR) and uterine volume. On average, compared to the TAH group, the TLH group had significantly longer OR time (163 vs. $130 \mathrm{~min}, p<0.001)$ and lower uterine volume (360 vs. $448 \mathrm{~cm}^{3}, p=0.026$ ). Both groups reported similar types of anesthesia, blood loss during surgery, blood transfusions, number of antibiotic use and proportion of patients receiving secondary procedures (all $p>0.05$ ). Regarding the effectiveness indicators, there were no significant differences between the two groups in rate of major surgical complications (primary effectiveness measure, including ureteral injury, bladder injury, fluid accumulating, EBL during surgery of more than $1000 \mathrm{ml}$, fever, incision dehiscence, intestinal obstruction, hospitalization of more than 30 days, and secondary suture) or discomfort symptoms (secondary effectiveness measure). Compared to patients who received TAH, patients who received TLH had a shorter length of hospital stay (9.91 days vs 13.00 days, $p<0.001$ ), shorter length of pre-operative stay (3.88 days vs 4.74 days, $p=0.005)$, and shorter length of post-operative stay (6.03 days vs 8.26 days, $p<0.001)$.

On average, it took significantly less time for patients in the TLH group to return to normal activity than the TAH group $(5.66 \pm 3.97$ weeks vs. $6.92 \pm 4.86$ weeks, $p=0.022)$. With regards to patients who returned to work, the difference was also significant between the TLH group requiring a shorter time and the TAH group $(6.97 \pm 3.42$ weeks vs. $8.08 \pm 3.62$ weeks, $p=0.0232)$.

Table 3 presents the costs per case between two patient groups. The average direct medical costs per case of TLH group was significantly higher than that of TAH 
Table 1 Socio-demographic and clinical characteristics

\begin{tabular}{|c|c|c|c|}
\hline Variable & $\operatorname{TLH}(n=75)$ & TAH $(n=317)$ & $P$ \\
\hline Age (years) & $45.88 \pm 4.13$ & $45.29 \pm 4.48$ & 0.299 \\
\hline Body Mass Index & $23.24 \pm 2.03$ & $23.71 \pm 2.61$ & 0.084 \\
\hline Number of births & & & 0.802 \\
\hline 0 & $1(1.33 \%)$ & $10(3.15 \%)$ & \\
\hline 1 & $42(56.00 \%)$ & $173(54.57 \%)$ & \\
\hline 2 & $24(32.00 \%)$ & $91(28.71 \%)$ & \\
\hline$\geq 3$ & $8(10.67 \%)$ & $41(13.56 \%)$ & \\
\hline Previous delivery & & & 0.086 \\
\hline None & $1(1.33 \%)$ & 10(3.15\%) & \\
\hline Vaginal & $71(94.67 \%)$ & $270(85.18 \%)$ & \\
\hline Cesarean & $3(4.00 \%)$ & $37(11.67 \%)$ & \\
\hline Menopause & & & 0.669 \\
\hline Yes & $3(4.00 \%)$ & $11(3.47 \%)$ & \\
\hline No & $72(96.00 \%)$ & $301(94.95 \%)$ & \\
\hline Unknown & $0(0 \%)$ & $5(1.58 \%)$ & \\
\hline Type of fibroid & & & $0.002^{*}$ \\
\hline Single & $40(53.33 \%)$ & 108(34.07\%) & \\
\hline Multiple & $35(46.67 \%)$ & $209(65.93 \%)$ & \\
\hline Size of fibroid & & & 0.142 \\
\hline$\geq 5 \mathrm{~cm}$ & $38(49.33 \%)$ & $186(58.68 \%)$ & \\
\hline$<5 \mathrm{~cm}$ & $37(50.67 \%)$ & $131(41.32 \%)$ & \\
\hline Previous abdominal operation & & & 0.054 \\
\hline Yes & $18(24.00 \%)$ & $113(35.65 \%)$ & \\
\hline No & $57(76.00 \%)$ & $204(64.35 \%)$ & \\
\hline Contraceptive ring & & & 0.131 \\
\hline Yes & $2(2.67 \%)$ & $25(7.96 \%)$ & \\
\hline No & $73(97.33 \%)$ & 289(92.04\%) & \\
\hline Disease severity on admission & & & 0.116 \\
\hline General & $75(100.00 \%)$ & $307(96.85 \%)$ & \\
\hline Severe & $0(0.00 \%)$ & 10(3.15\%) & \\
\hline Comorbidity & & & 0.328 \\
\hline None & $36(48.00 \%)$ & $128(41.84 \%)$ & \\
\hline One & $27(36.00 \%)$ & $116(36.48 \%)$ & \\
\hline$\geq$ Two & $12(16.00 \%)$ & $73(21.68 \%)$ & \\
\hline Insurance status & & & 0.116 \\
\hline NCMS & $36(48.00 \%)$ & $130(41.01 \%)$ & \\
\hline URBMI & $31(41.33 \%)$ & $113(35.65 \%)$ & \\
\hline UEBMI & $6(8.00 \%)$ & $52(16.40 \%)$ & \\
\hline Uninsured & $2(2.67 \%)$ & $22(6.94 \%)$ & \\
\hline Employment status & & & 0.125 \\
\hline Unemployed & $7(9.33 \%)$ & 29(9.15\%) & \\
\hline Employed & $64(85.33 \%)$ & $283(89.27 \%)$ & \\
\hline Retired & $4(5.33 \%)$ & $5(1.58 \%)$ & \\
\hline Living location & & & 0.664 \\
\hline Xi'an City, Shaanxi Province & $26(34.67 \%)$ & $127(40.06 \%)$ & \\
\hline Other cities in Shaanxi Province & $46(61.33 \%)$ & $177(55.84 \%)$ & \\
\hline Other Provinces & $3(4.00 \%)$ & $13(4.10 \%)$ & \\
\hline
\end{tabular}

Note, The data are presented as the mean $\pm S D$ for continuous variables and as number and percentage (\%) for categorical variables. The $p$-value was derived by two-sample t test for continuous variables and by Pearson's Chi-square or Fisher's exact test for categorical variables; NCMS,.New Cooperative Medical Scheme, URBMI, Urban Resident Basic Medical Insurance, UEBMI, Urban Employee Basic Medical Insurance. $T A H$, total abdominal hysterectomy, $T L H$, total laparoscopic hysterectomy; ${ }^{*} p<0.05$ group (US $\$ 2,898.90$ vs. US $\$ 2,406.88, p<0.001$ ). Combining the statistically indifferent direct non-medical costs, the average direct costs per case of the TLH group significantly higher than that of TAH group (US\$2,925.71 vs. US $\$ 2,436.14, p<0.001)$. The average indirect medical costs per case of TLH groups was significantly higher than that of TAH groups (US $\$ 1,133.22$ vs. US $\$ 1,394.85$, $p=0.006$ ). Time costs of patients were not significantly different between the TAH group and the TAH group (US $\$ 887.42$ vs. US $\$ 1,048.43, p=0.057$ ). Significant difference was observed for the time costs of family members, where the TLH group was lower than the TAH group (US\$887.42 vs. US $\$ 1048.43, p<0.001$ ). Total costs per case was higher, although not attaining statistical significance, for TLH group compared with TAH group (US $\$ 4,058.93$ vs. US $\$ 3,830.98, p=0.053$ ). Fig. 2 shows that results of sensitivity analysis demonstrated the mean indirect costs was robust.

Table 4 lists the adjusted increment costs and effect and the incremental cost effectiveness ratios. When costs were adjusted for the difference in patient mix by GLM, there were significantly higher total costs for the TLH group versus the TAH group with a mean difference of US\$ 256.86. Compared to the TAH group, the TLH group had a lower rate of major surgical complications of $4.53 \%$ (95\% CI: $4.35 \%$ to $4.71 \%$ ); a shorter time to return to normal activities of 1.27 weeks (95\% CI: 1.23 weeks to 1.30 weeks); and, a lower rate of discomfort symptoms of $6.75 \%$ (95\% CI: $6.45 \%$ to $7.05 \%$ ). The incremental costs for reducing one patient with major surgical complications in the TLH group compared to the TAH group were US $\$ 5,669.16$ (95\% CI: $\$ 5,384.76$ to $\$ 5,955.56$ ). The incremental costs for reducing one patient with postoperative discomfort symptoms in the TLH group compared to the TAH group were US $\$ 38.02$ (95\% CI: $\$ 36.35$ to $\$ 39.68$ ). In addition, the additional costs for reducing the time required until the patient could return to normal activities by one-week, was US\$ 202.96 (95\% CI: \$194.97 to $\$ 210.95$ ).

\section{Discussion}

Overall, we found that TLH demonstrated cost effectiveness than TAH from a societal perspective. It was associated with an ICER of $\$ 56.69$ (95\% CI: $\$ 53.84$ to $\$ 59.55$ ) per $1 \%$ reduction in major surgical complications and an ICER of $\$ 38.02$ (95\% CI: $\$ 36.35$ to $\$ 39.68$ ) per $1 \%$ reduction in discomfort symptoms. Our findings are in line with previous relevant literature which adopted the major complications rate as the primary effect measure $[24,28,52,53]$.

On average, $\$ 5,669.16$ was invested to prevent one additional major complication when performing a TLH instead of a TAH. Although cost estimate may vary due 
Table 2 Surgical data and clinical outcomes

\begin{tabular}{|c|c|c|c|}
\hline Variable & $\operatorname{TLH}(n=75)^{1}$ & TAH $(n=317)$ & $P$ \\
\hline Anesthesia & & & 0.252 \\
\hline General anesthesia & $75(100.00 \%)$ & $303(95.58 \%)$ & \\
\hline Combined spinal epidural anesthesia & $0(0.00 \%)$ & $13(4.10 \%)$ & \\
\hline Epidural anesthesia & $0(0.00 \%)$ & $1(0.32 \%)$ & \\
\hline Time in operating room (minutes) & 165(140-205) & 130(110-150) & $<0.001^{*}$ \\
\hline Blood loss for surgery (ml) & $200(100-300)$ & $100(80-200)$ & 0.139 \\
\hline Received blood transfusion & & & 0.782 \\
\hline Yes & $15(20.00 \%)$ & $59(18.61 \%)$ & \\
\hline No & $60(80 \%)$ & $258(81.39 \%)$ & \\
\hline Uterine volume (cm3) & $360(224-607.75)$ & $448(280-780)$ & $0.026^{*}$ \\
\hline Antibiotic types & & & 0.162 \\
\hline One & $20(26.66 \%)$ & $55(17.35 \%)$ & \\
\hline Two & $53(70.67 \%)$ & $246(77.60 \%)$ & \\
\hline Three & $2(2.67 \%)$ & $16(5.05 \%)$ & \\
\hline Secondary Procedures (\% of patients) & & & 0.895 \\
\hline Yes & $13(17.33 \%)$ & $57(17.98 \%)$ & \\
\hline No & $62(82.67 \%)$ & $260(82.02 \%)$ & \\
\hline Rate of major surgical complications & $4(5.33 \%)$ & $31(9.78 \%)$ & 0.161 \\
\hline Ureteral injury & $1(1.33 \%)$ & $0(0 \%)$ & 0.191 \\
\hline Bladder injury & $0(0 \%)$ & $1(0.32 \%)$ & 0.809 \\
\hline Blood Loss for Surgery more than $1000 \mathrm{ml}$ & $0(0 \%)$ & $4(1.26 \%)$ & 0.426 \\
\hline Fever & $2(2.67 \%)$ & $23(7.26 \%)$ & 0.109 \\
\hline Incision dehiscence & $0(0 \%)$ & $3(0.95 \%)$ & 0.528 \\
\hline Intestinal obstruction & $0(0 \%)$ & 1 & 0.809 \\
\hline Hospitalization more than 30 days & $1(1.33 \%)$ & $3(0.95 \%)$ & 0.574 \\
\hline Secondary suture & $1(1.33 \%)$ & $4(1.26 \%)$ & 0.656 \\
\hline Pre-operative length of stay (LOS) & $3.88 \pm 2.23$ & $4.74 \pm 2.59$ & $0.005^{*}$ \\
\hline Post-operative LOS & $6.03 \pm 7.11$ & $8.26 \pm 3.90$ & $<0.001^{*}$ \\
\hline LOS & $9.91 \pm 7.70$ & $13.00 \pm 4.87$ & $<0.001^{*}$ \\
\hline Time to normal activity(weeks) & $5.66 \pm 3.97$ & $6.92 \pm 4.86$ & $0.022^{*}$ \\
\hline Back to work(weeks) & $6.97 \pm 3.42$ & $8.08 \pm 3.62$ & $0.023^{*}$ \\
\hline Discomfort symptoms & & & 0.217 \\
\hline Yes & $13(17.33 \%)$ & $76(23.97 \%)$ & \\
\hline No & $62(82.67 \%)$ & $241(76.03 \%)$ & \\
\hline
\end{tabular}

Note, Data are presented as the median with the interquartile range (IQR, Q1-Q3) or the mean \pm SD for continuous variables and as the number and percentage (\%) for categorical variables. The $p$-value was derived by using the Mann-Whitney $\mathrm{U}$ test or two-sample t test for continuous variables and by using the Pearson's Chi-square test for categorical variables. ${ }^{1}$ Conversion from TLH to TAH was one of 75 (1.33\%). ${ }^{*} p<0.05$

Table 3 Mean costs per case between the TLH and TAH groups (in 2020 US\$)

\begin{tabular}{lcrr}
\hline & TLH & TAH & P \\
\hline Direct costs & $2,925.71 \pm 712.04$ & $2,436.14 \pm 557.63$ & $<0.001^{*}$ \\
Direct medical costs & $2,898.90 \pm 708.63$ & $2,406.88 \pm 556.1$ & $<0.001^{*}$ \\
Direct non-medical costs & $26.81 \pm 34.13$ & $29.26 \pm 47.46$ & 0.615 \\
Indirect costs & $1,133.22 \pm 637.56$ & $1,394.85 \pm 728.53$ & $0.006^{*}$ \\
Time costs of patients & $887.42 \pm 602.93$ & $1,048.43 \pm 655.72$ & 0.057 \\
Time costs of family members & $245.80 \pm 111.74$ & $346.42 \pm 213.18$ & $<0.001^{*}$ \\
Total costs & $4,058.93 \pm 931.78$ & $3,830.98 \pm 949.22$ & 0.053 \\
\hline
\end{tabular}

Note, Data are presented as the mean $\pm S D$, The $\mathrm{p}$-value was obtained by using the Mann-Whitney $\mathrm{U}$ test; ${ }^{*} p<0.05$ 


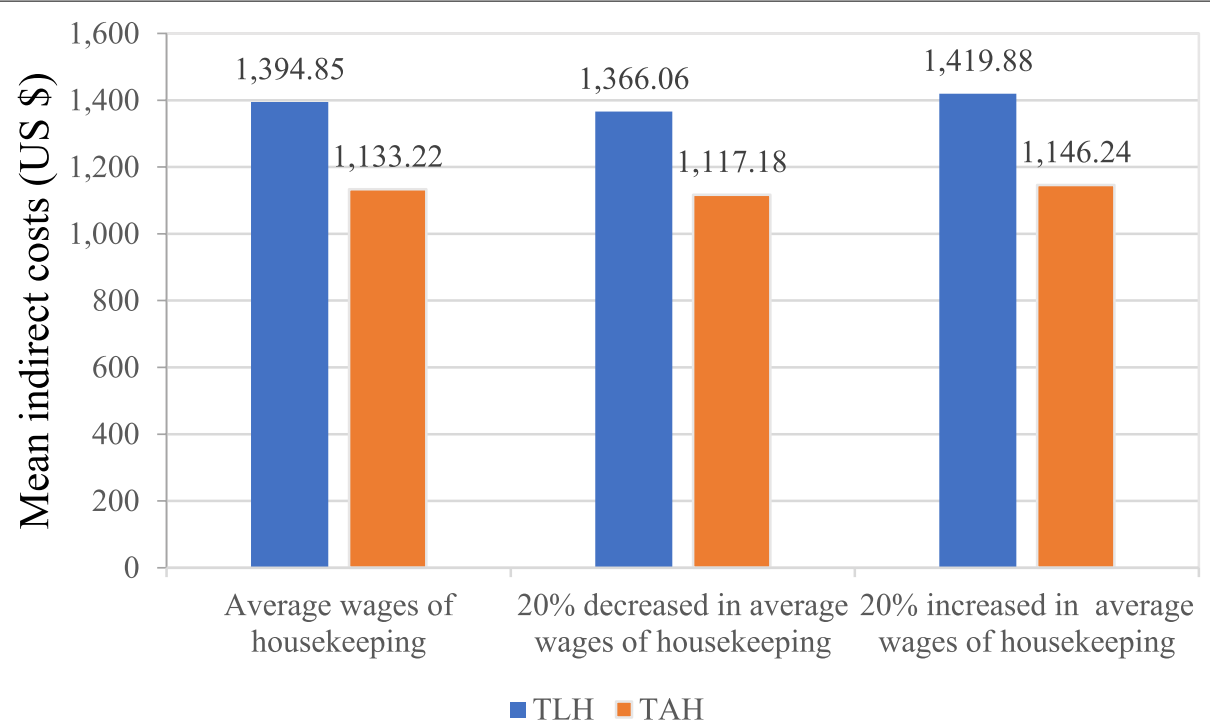

Fig 2. Sensitivity analysis for indirect costs by productivity losses of retired/nonworking patients.

Table 4 Cost effectiveness of TLH versus TAH for uterine fibroids

\begin{tabular}{ll}
\hline & Adjusted difference (95\% Cls) \\
\hline Increment costs, 2020 US\$ & $256.86(249.03,264.69)$ \\
Increment effect & \\
Rate of major surgical complications, \% & $-4.53(-4.71,-4.35)$ \\
Rate of discomfort symptoms, \% & $-6.75(-7.05,-6.45)$ \\
Time to normal activity, weeks & $-1.27(-1.30,-1.23)$ \\
ICER (Rate of major surgical complica- & $-56.69(-59.55,-53.84)$ \\
tions) & \\
ICER (Rate of discomfort symptoms) & $-38.02(-39.68,-36.35)$ \\
ICER (Time to normal activity) & $-202.96(-210.95,-194.97)$ \\
\hline
\end{tabular}

Note, ICER, incremental cost effectiveness ratio. 95\%Cl, 95\% Coefficient Interval

to differences in perspectives, patient populations, and measurement, most of the published literature favours TLH over TAH regarding overall cost effectiveness [24, $30,54,55]$. A Dutch randomized trial study found that the TLH is cost effective compared to TAH [52]. Our study reported that the additional costs for reducing one major complication in the TLH group was $\$ 5,669.16$ as compared to the TAH group. Furthermore, it also found that the higher operative procedure costs for TLH were offset by a shorter LOS for TAH. Further subgroup analysis of the Dutch trial data reported that TLH is cost effective for patients over 70 years of age, but not for patients with a $B M I>35 \mathrm{~kg} / \mathrm{m}^{2}$ [53]. This study did not capture and analyze, however, the indirect costs of any productivity losses. Furthermore, the TLH and TAH were performed in early endometrial cancer cases, which require more medical resources to treat than uterine fibroids. A systematic review comparing costs and short-term effects between laparoscopic hysterectomy and abdominal hysterectomy, in which twelve prospective trials concerning 2,226 patients in total were reviewed, indicated an ICER of $\$ 35,750$ to reduce one major complication for laparoscopic hysterectomy compared to abdominal hysterectomy [24]. Noticeably, all these patients had a benign indication for hysterectomy.

According to this threshold of cost to prevent one additional complication to be $\$ 10,995$ in our study, TLH was a cost-effective alternative to TAH for uterine fibroids in China. Considering that TLH has better long-term outcomes than TAH $[23,24,26,53,54,56]$, it is also possible that when incorporating additional longer-term benefits, TLH would become even cost effective than TAH over time.

We have shown that the mean unadjusted total costs of TLH is higher than TAH (US $\$ 4,058.93$ vs US $\$ 3,830.98$ ). This is mainly due to the medical costs in the hospital, which is consistent with the previous literature [24, 38]. Wright et al. also reported that mean total patient costs were US $\$ 43,622$, US $\$ 31,934$ and US $\$ 38,312$ for laparoscopic hysterectomy, abdominal hysterectomy and vaginal hysterectomy, respectively, for benign indications [26]. Our data shows that TLH had higher direct costs but lower indirect costs compared to TAH. The higher direct costs of TLH could be offset by the lower indirect costs to some extent. This is consistent with the previous reports from Sweden and China [13, 38, 57]. The study by Leng et al. from China reported the total costs were $\$ 1,065$ (direct costs $\$ 867$, indirect cost $\$ 198$ ) in laparoscopic hysterectomy, and $\$ 1,050$ (direct costs $\$ 749$, indirect cost \$301) in TAH, at 28 days after hysterectomy 
[38]. The length of follow-up period (12-month in our study vs. 28-day in Leng et al.) and the items considered in the indirect costs (i.e. the productivity losses of both patients and caregivers were considered in our study) may explain the differences in estimated costs. However, a study from Canada found that the total costs of TLH are less than TAH for benign reasons [26], and Barnett et al. reported that total costs of TLH are less than TAH for endometrial cancer patients from a societal prospective [58]. A review showed that direct costs in the laparoscopic hysterectomy group were $6.1 \%$ higher than that in the abdominal hysterectomy group ( $\$ 63,997$ vs $\$ 60,114)$, and the indirect costs of laparoscopic hysterectomy were $50 \%$ of the indirect costs of abdominal hysterectomy $(\$ 1,609$ vs $\$ 3,139)$ [24].

With respect to the effect, the TLH group tends to have both lower rate of major surgical complications and lower rate of postoperative discomfort symptoms, and shorter LOS and shorter time back to normal actives compared to TAH. These findings are consistent with the empirical studies conducted elsewhere in the world [13, 22, 25, 26, 59, 60]. Empirical studies from the US [26, 61], the Netherlands [52, 53, 60, 62], the UK [25] and China [63] all report that TLH had lower but insignificant complications rates compared to TAH. In addition, several studies from the US [41] and from Germany [64] report that TLH was associated with significantly lower overall rate of intraoperative complications and minor postoperative complications than TAH.

Regarding the LOS and postoperative hospitalization period, consistent with the literature, both indicators are statistically significantly shorter in the TLH group [23, 41, 65]. However, in our study, the LOS and postoperative LOS are longer compared to other studies conducted in developed countries. The fee-forservice payment system adopted in China may be the main explanation for the difference. Health care providers have an incentive to keep patients in hospital longer [66]. The difference in medical technology levels between China and other developed countries could be another possible reason.

The main strength of our study is that it presents the first analysis of the incremental cost effectiveness of TAH and TLH for patients with uterine fibroids in mainland China, not to mention in Western China. In addition, this study assessed not only the direct costs, but also the productivity losses of patients and caregivers. Moreover, we followed up 12-month period to obtain the data of costs and outcomes. The findings provide useful information for researchers to conduct further cost effectiveness analysis based on prospective study which can provide stronger and more evidence, in China. In addition, the data may be useful for Chinses health care policy-makers and medical insurance payers to make related health care decision.

A few limitations should be considered when interpreting the results of this study. Firstly, this is a retrospective study and our patients are from a single hospital, thus a sample selection issue may exist and potentially limit the generalization of our findings. Secondly, using all major surgical complications as the primary measure of effectiveness, assumes that each type of major surgical complication is fundamentally equivalent to each other. Thirdly, this study only followed patients for 12 months. The long-run quality of life effects for the different patient groups was not studied. Fourthly, by the time this study was conducted, new surgical procedures, such as robotic-assisted laparoscopic surgery for hysterectomy, have flourished in the developed countries [26, 67-69]. However, to date, such new techniques have not been widely adopted in China.

\section{Conclusions}

In conclusion, according to our study, TLH is cost effective compared to TAH, based on a threshold calculated at $\$ 10,995$, to prevent one additional complication in China. Further randomized, prospective studies would be an ideal way to further explore the incremental costs and long-run health-related quality of life of different hysterectomy procedures in China.

\section{Abbreviations}

TAH: Total abdominal hysterectomy; TLH: Total laparoscopic hysterectomy; ICER: Incremental cost effectiveness ratio; LOS: Length-of-hospital stay; QOL: Quality of life; QALYs: Quality-adjusted life years; GDP: Gross domestic product; BMI: Body mass index; EBL: Estimated blood loss; GLM: General liner models; SD: Standard deviation; NCMS: New Cooperative Medical Scheme; URBMI: Urban Resident Basic Medical Insurance; UEBMI: Urban Employee Basic Medical Insurance; 95\%Cl: 95\% Coefficient Interval.

\section{Acknowledgements}

The authors thank all patients who participated in the study for their selfless collaboration in the study. We would also like to thank the staff of the medical records and statistics department of the first affiliated hospital of Xi'an Jiaotong University, for their co-operation and their kind assistance in the field data collection. We also thank Dr. Wanyue Dong, Dr. Chi Shen, Dr. Min Su and Xinhong Zhang and Dan Wang for participating in the data collection.

\section{Authors' contributions}

Conceptualization, J.Y., X.F. and J.G.; data curation, J.Y.; formal analysis, J.Y., Y.X. and G.C.; writing —original draft preparation, J.Y., X.F. and D.L.; writing —review and editing, J.Y., D.L. and G.C.; supervision, J.G. and G.C.; funding acquisition, X.F. and J.G. All authors have read and agreed to the published version of the manuscript.

\section{Funding}

This research was funded by the China Medical Board (grant number: 09-986) and the National Natural Science Foundation (grant number: 72004178).

\section{Availability of data and materials}

The data presented in current study are available on reasonable request from the corresponding author. 


\section{Declarations}

\section{Ethics approval and consent to participate}

This study was performed in accordance with the Ethical Principles for Medica Research Involving Human Subjects (Declaration of Helsinki). Ethics approval and consent for the study was approved by the Ethics Committee of the Xi'an Jiaotong University Health Science Center (approval date: 30/6/2014). Prior to the telephone interview, verbal consent was obtained from all subjects involved in the study. All patient information was anonymised and de-identified prior to analysis.

\section{Consent for publication}

Not applicable.

\section{Competing interests}

The authors declare no conflict of interest. The funders had no role in the design of the study; in the collection, analyses, or interpretation of data; in the writing of the manuscript, or in the decision to publish the results.

\section{Author details}

'School of Public Health, Xi'an Jiaotong University Health Science Center, Xi'an 710061, People's Republic of China. ${ }^{2}$ School of Public Policy and Administration, Xi'an Jiaotong University, Xi'an 710049, People's Republic of China. ${ }^{3}$ School of Public Management, Northwest University School, Xi'an 710127, People's Republic of China. ${ }^{4}$ Monash Business School, Monash University, Clayton, VIC 3145, Australia.

Received: 6 August 2021 Accepted: 15 February 2022

Published online: 24 February 2022

\section{References}

1. Stewart EA. Uterine fibroids. Lancet. 2001;357(9252):293-8. https://doi. org/10.1016/S0140-6736(00)03622-9.

2. Zimmermann A, Bernuit D, Gerlinger C, Schaefers M, Geppert K. Prevalence, symptoms and management of uterine fibroids: an international internet-based survey of 21,746 women. BMC Womens Health. 2012;12(1):6. https://doi.org/10.1186/1472-6874-12-6.

3. Stewart EA, Laughlin-Tommaso SK, Catherino WH, Lalitkumar S, Gupta D, Vollenhoven B. Uterine fibroids Nat Rev Dis Primers. 2016;2(1):16043. https://doi.org/10.1038/nrdp.2016.43.

4. Baird DD, Dunson DB, Hill MC, Cousins D, Schectman JM. High cumulative incidence of uterine leiomyoma in black and white women: ultrasound evidence. Am J Obstet Gynecol. 2003;188(1):100-7. https://doi.org/10. 1067/mob.2003.99

5. Okolo S. Incidence, aetiology and epidemiology of uterine fibroids. Best Pract Res Clin Obstet Gynaecol. 2008;22(4):571-88. https://doi.org/10. 1016/j.bpobgyn.2008.04.002.

6. Kjerulff KH, Rhodes JC, Langenberg PW, Harvey LA. Patient satisfaction with results of hysterectomy. Am J Obstet Gynecol. 2000;183(6):1440-7. https://doi.org/10.1067/mob.2000.107731.

7. Stang A, Merrill RM, Kuss O. Hysterectomy in Germany: a DRG-based nationwide analysis, 2005-2006. Dtsch Arztebl Int. 2011;108(30):508-14 https://doi.org/10.3238/arztebl.2011.0508

8. Hill EL, Graham ML, Shelley JM. Hysterectomy trends in Aus tralia-between 2000/01 and 2004/05. Aust N Z J Obstet Gynaecol. 2010;50(2):153-8. https://doi.org/10.1111/j.1479-828X.2009.01130.x.

9. Prusty RK, Choithani C, Gupta SD. Predictors of hysterectomy among married women 15-49 years in India. Reprod Health. 2018;15(1):3. https://doi. org/10.1186/s12978-017-0445-8

10 Garry R. Health economics of hysterectomy. Best Pract Res Clin Obstet Gynaecol. 2005;19(3):451-65. https://doi.org/10.1016/j.bpobgyn.2005.01.010.

11. Merrill RM. Hysterectomy surveillance in the United States, 1997 through 2005. Med Sci Monit. 2008;14(1):Cr24-31.

12 Cardozo ER, Clark AD, Banks NK, Henne MB, Stegmann BJ, Segars JH. The estimated annual cost of uterine leiomyomata in the United States. Am J Obstet Gynecol. 2012;206(3):211 e1-9. https://doi.org/10.1016/j.ajog.2011.12.002.

13 Gu Y, Zhu L, Liu A, Ma J, Lang J. Analysis of hysterectomies for patients with uterine leiomyomas in China in 2010. Int J Gynecol Obstet. 2015;129(1):71-4. https://doi.org/10.1016/j.ijgo.2014.10.031.
14 Pitter MC, Simmonds C, Seshadri-Kreaden U, Hubert HB. The impact of different surgical modalities for hysterectomy on satisfaction and patient reported outcomes. Interact J Med Res. 2014;3(3):e11. https://doi.org/10. 2196/ijmr.3160

15 Owen C, Armstrong AY. Clinical management of leiomyoma. Obstet Gynecol Clin North Am. 2015;42(1):67-85. https://doi.org/10.1016/j.ogc. 2014.09.009.

16 Loring M, Morris SN, Isaacson KB. Minimally invasive specialists and rates of laparoscopic hysterectomy. JSLS. 2015;19(1):e2014.00221. https://doi. org/10.4293/jsls.2014.00221

17 Wright JD, Ananth CV, Tergas Al, Herzog TJ, Burke WM, Lewin SN, Lu YS, Neugut Al, Hershman DL. An economic analysis of robotically assisted hysterectomy. Obstet Gynecol. 2014;123(5):1038-48. https://doi.org/10. 1097/aog.0000000000000244

18. Johnson N, Barlow D, Lethaby A, Tavender E, Curr E, Garry R. Surgical approach to hysterectomy for benign gynaecological disease. Cochrane Database Syst Rev. 2006;2:CD003677. https://doi.org/10.1002/14651858. CD003677.pub3.

19 Lee DW, Gibson TB, Carls GS, Ozminkowski RJ, Wang S, Stewart EA. Uterine fibroid treatment patterns in a population of insured women. Fertil Steril. 2009;91(2):566. https://doi.org/10.1016/j.fertnstert.2007.12.004.

20. Luo C, Liu M, Li X. Efficacy and safety outcomes of robotic radical hysterectomy in Chinese older women with cervical cancer compared with laparoscopic radical hysterectomy. BMC Womens Health. 2018;18(1):61. https://doi.org/10.1186/s12905-018-0544-x.

21 Eggemann $\mathrm{H}$, Ignatov A, FrauchigerHeuer $\mathrm{H}$, Amse T, Costa SD. Laparoscopic-assisted vaginal hysterectomy versus vaginal hysterectomy for benign uterine diseases: a prospective, randomized, multicenter, double-blind trial. Arch Gynecol Obstet. 2018;297(2):479. https://doi.org/ 10.1007/s00404-017-4647-7

22. Aarts JW, Nieboer TE, Johnson N. Tavender E Garry R, Mol BW, Kluivers KB, Surgical approach to hysterectomy for benign gynaecological disease. Cochrane Database Syst Rev. 2015;2015(8):CD003677. https://doi.org/10. 1002/14651858.CD003677.pub5.

23 Lenihan JP, Kovanda C, Cammarano C. Comparison of laparoscopicassisted vaginal hysterectomy with traditional hysterectomy for costeffectiveness to employers. Am J Obstet Gynecol. 2004;190(6):1714-20. https://doi.org/10.1016/j.ajog.2004.02.059.

24 Bijen CB, Vermeulen KM, Mourits MJ, de Bock GH. Costs and effects of abdominal versus laparoscopic hysterectomy: systematic review of controlled trials. PLoS ONE. 2009;4(10):e7340. https://doi.org/10.1371/journal. pone.0007340.

25 Ghosh D, Wipplinger P, Byrne DL. Can total laparoscopic hysterectomy replace total abdominal hysterectomy? A 5-year prospective cohort study of a single surgeon's experience in an unselected population. Gynecol Surg. 2013;10(2):109-15. https://doi.org/10.1007/s10397-012-0754-4.

26 Wright KN, Jonsdottir GM, Jorgensen S, Shah N, Einarsson Jl. Costs and outcomes of abdominal, vaginal, laparoscopic and robotic hysterectomies. JSLS. 2012;16(4):519. https://doi.org/10.4293/108680812X13462 882736736

27 Duangpirom W, Pattanaprateep O, Vallibhakara O, Hongsakorn W Sophonsritsuk A. Cost-Utility Analysis of Total Abdominal Versus Total Laparoscopic Hysterectomy in a Thai University Hospital. J Gynecol Surg. 2021;37(2):132. https://doi.org/10.1089/gyn.2020.0108.

28. Garry R. Fountain, J Brown, J Manca, A Mason S, Sculpher M, Napp V Bridgman S, Gray J, Lilford R, EVALUATE hysterectomy trial: a multicentre randomised trial comparing abdominal, vaginal and laparoscopic methods of hysterectomy. Health Technol Assess. 2004;8(26):1-154. https://doi. org/10.3310/hta8260

29. Rutstein SE, Siedhoff MT, Geller EJ, Doll KM, Wu JM, Clarke-Pearson DL Wheeler SB. Cost-Effectiveness of Laparoscopic Hysterectomy With Morcellation Compared With Abdominal Hysterectomy for Presumed Myomas. J Minim Invasive Gynecol. 2016;23(2):223. https://doi.org/10. 1016/j.jmig.2015.09.025.

30. Graves N, Janda M, Merollini K, Gebski V, Obermair A. The cost-effectiveness of total laparoscopic hysterectomy compared to total abdominal hysterectomy for the treatment of early stage endometrial cancer. BMJ Open. 2013;3(4):e001884. https://doi.org/10.1136/bmjopen-2012-001884

31 Sculpher M, Manca A, Abbott J, Fountain J, Mason S, Garry R. Cost effectiveness analysis of laparoscopic hysterectomy compared with standard 
hysterectomy: results from a randomised trial. BMJ Clinical research ed. 2004;328(7432):134. https://doi.org/10.1136/bmj.37942.601331.EE.

32. Sheyn D, Mahajan S, Billow M, Fleary A, Hayashi E, El-Nashar SA. Geographic Variance of Cost Associated With Hysterectomy. Obstet Gynecol. 2017;129(5):844-53. https://doi.org/10.1097/AOG.0000000000001966.

33. Li GY, Shang HL, Chen LS. Analysis of operative patterns of 2272 laparoscopic hysterectomies. Chin J Obstet Gynecol. 2005;40(3):168-70. https:// doi.org/10.3760/j.issn:0529-567×.2005.03.007.

34. Liang C, Liu P, Cui Z, Liang Z, Bin X, Lang J, Chen C. Effect of laparoscopic versus abdominal radical hysterectomy on major surgical complications in women with stage IA-IIB cervical cancer in China, 2004-2015. Gynecol Oncol. 2020;156(1):115-23. https://doi.org/10.1016/j.ygyno.2019.10.032.

35. Zhu L, Lang JH, Liu CY, Shi HH, Sun ZJ, Fan R. Clinical assessment for three routes of hysterectomy. Chin Med J (Engl). 2009:122(4):377-80.

36. Huang XY, Fang SH, Wang MZ, Liu ZC, Zhang SY, Chen QB. Clinical study on different operation procedure for hysterectomy. Chin J Obstet Gynecol. 2005;40(10):652-5. https://doi.org/10.3760/j.issn:0529-567x. 2005.10.002.

37. He H, Yang Z, Zeng D, Fan J, Hu X, Ye Y, Bai H, Jiang Y, Lin Z, Lei Z, Li X, Li L, Gan J, Lan Y, Tang X, Wang D, Jiang J, Wu X, Li M, Ren X, Yang X, Liu $M$, Wang $Q$, Jiang $F$, Li L, Comparison of the short-term and long-term outcomes of laparoscopic hysterectomies and of abdominal hysterectomies: a case study of 4,895 patients in the Guangxi Zhuang Autonomous Region, China. Chin J Cancer Res 2016:28(2):187 https://doi.org/10. 21147/j.issn.1000-9604.2016.02.06

38. Leng JH, Lang JH, Li HJ, Liu ZF, Sun DW, Zhu L. Effect of different surgical approaches on quality of life and cost-consequence. Chin J Obstet Gynecol. 2004;39(5):315. https://doi.org/10.3760/j.issn:0529-567x.2004.05.008

39. Tan XJ, Lang JH, Shen K, Liu ZF, Sun DW, Leng JH, Zhu L. Operative approaches, indications, and medical economics evaluation of 4180 cases of hysterectomy. Acta Acad Med Sin. 2003;25(4):406-9 (In Chinese)

40. Aksu F, Gezer A, Oral E. Seventeen-year review of hysterectomy procedures in a university clinic in Istanbul 1985-2001. Arch Gynecol Obstet. 2004;270(4):217-22. https://doi.org/10.1007/s00404-003-0546-1.

41 Jonsdottir GM, Jorgensen S, Cohen SL, Wright KN, Shah NT, Chavan N, Einarsson Jl. Increasing minimally invasive hysterectomy: effect on cost and complications. Obstet Gynecol. 2011;117(5):1142-9. https://doi.org/ 10.1097/AOG.0b013e3182166055.

42 Weinstein MC. Principles of cost-effective resource allocation in health care organizations. Int J Technol Assess Health Care. 1990;6(1):93-103. https://doi.org/10.1017/s0266462300008953.

43 Posnett J, Jan S. Indirect cost in economic evaluation: the opportunity cost of unpaid inputs. Health Econ. 1996;5(1):13-23. https://doi.org/10. 1002/(sici)1099-1050(199601)5:1\%3c13::Aid-hec182\%3e3.0.Co;2-j.

44. Barral M, Rabier H, Termoz A, Serrier H, Colin C, Haesebaert J, Derex L, Nighoghossian N, Schott AM, Viprey M, et al. Patients' productivity losses and informal care costs related to ischemic stroke: a French population-based study. Eur J Neurol. 2021;28(2):548. https://doi.org/10.1111/ene.14585.

45. Xie F, Thumboo J, Fong KY, Lo NN, Yeo SJ, Yang KY, Li SC, A Study on Indirect and Intangible Costs for Patients with Knee Osteoarthritis in Singapore. Value Health 2008:11 84 https://doi.org/10.1111/j.1524-4733. 2008.00371.x

46. Shaan Xi Statistical Yearbook 2013. Available online: http://tij.shaanxi.gov. cn/upload/2021/zl/2013/zk/indexch.htm (accessed on 5 Jan. 2022)

47. Yearly Average Currency Exchange Rates. Available online: https://www. irs.gov/zh-hans/individuals/international-taxpayers/yearly-average-curre ncy-exchange-rates (accessed on 5 Jan. 2022)

48. World Health Organization. The world health report 2002- Reducing Risks, Promoting Healthy Life. Available online: https://www.who.int/whr/ 2002/en/whr02_en.pdf. (accessed July 9, 2021).

49. China GDP Per Capita 1960-2022. Available online: https://www.macro trends.net/countries/CHN/china/gdp-per-capita. (accessed on 5 Jan. 2022)

50 White IR, Royston P, Wood AM. Multiple imputation using chained equations: Issues and guidance for practice. 2011;30(4):377. https://doi.org/10. 1002/sim.4067.

51. Rubin DB. Multiple Imputation for Nonresponse in Surveys. New York: John Wiley \& Sons Inc; 1987.

52. Bijen $C B$, Vermeulen KM, Mourits MJ, Arts HJ, Ter Brugge HG, van der Sijde R, Wijma J, Bongers MY, van der Zee AG, de Bock GH. Cost effectiveness of laparoscopy versus laparotomy in early stage endometrial cancer: a randomised trial. Gynecol Oncol. 2011;121(1):76. https://doi.org/10. 1016/j.ygyno.2010.11.043.

53. Bijen $\mathrm{CB}$, de Bock $\mathrm{GH}$, Vermeulen $\mathrm{KM}$, Arts $\mathrm{HJ}$, ter Brugge $\mathrm{HG}$, van der Sijde R, Kraayenbrink AA, Bongers MY, van der Zee AG, Mourits MJ. Laparoscopic hysterectomy is preferred over laparotomy in early endometrial cancer patients, however not cost effective in the very obese. Eur J Cancer. 2011;47(14):2158-65. https://doi.org/10.1016/j.ejca.2011.04.035.

54 Warren L, Ladapo JA, Borah BJ, Gunnarsson CL. Open abdominal versus laparoscopic and vaginal hysterectomy: analysis of a large United States payer measuring quality and cost of care. J Minim Invasive Gynecol. 2009;16(5):581-8. https://doi.org/10.1016/j.jmig.2009.06.018.

55 Hauspy J, Jiménez W, Rosen B, Gotlieb WH, Fung-Kee-Fung M, Plante M. Laparoscopic surgery for endometrial cancer: a review. J Obstet Gynaecol Can. 2010;32(6):570-9. https://doi.org/10.1016/s1701-2163(16)34526-1.

56 Devlin N, Parkin D. Does NICE have a cost-effectiveness threshold and what other factors influence its decisions? A binary choice analysis. Health Econ. 2004;13(5):437-52. https://doi.org/10.1002/hec.864.

57 Ellstrom M, Ferraz-Nunes J, Hahlin M, Olsson JH. A randomized trial with a cost-consequence analysis after laparoscopic and abdominal hysterectomy. Obstet Gynecol. 1998;91 (1):30. https://doi.org/10.1016/s00297844(97)00579-6

58. Barnett JC, Judd JP, Wu JM, Scales CD Jr. Myers ER, Havrilesky LJ, Cost comparison among robotic, laparoscopic, and open hysterectomy for endometrial cancer. Obstet Gynecol. 2010;116(3):685-93. https://doi.org/ 10.1097/AOG.0b013e3181ee6e4d.

59. Allam IS, Makled AK, Gomaa IA, El Bishry GM, Bayoumy HA, Ali DF. Total laparoscopic hysterectomy, vaginal hysterectomy and total abdominal hysterectomy using electrosurgical bipolar vessel sealing technique: a randomized controlled trial. Arch Gynecol Obstet. 2015;291(6):1341-5. https://doi.org/10.1007/s00404-014-3571-3.

60. Mourits MJ, Bijen CB, Arts HJ, ter Brugge HG, van der Sijde R, Paulsen L, Wijma J, Bongers MY, Post WJ, van der Zee AG, de Bock GH. Safety of laparoscopy versus laparotomy in early-stage endometrial cancer: a randomised trial. Lancet Oncol. 2010;11(8):763-71. https://doi.org/10.1016/ S1470-2045(10)70143-1.

61 Campbell ES, Xiao H, Smith MK. Types of hysterectomy. Comparison of characteristics hospital costs, utilization and outcomes. J Reprod Med. 2003:48(12):943.

62. Kluivers KB, Hendriks JC, Mol BW, Bongers MY, Bremer GL, de Vet HC, Vierhout ME, Brolmann HA. Quality of life and surgical outcome after total laparoscopic hysterectomy versus total abdominal hysterectomy for benign disease: a randomized, controlled trial. J Minim Invasive Gynecol. 2007;14(2):145-52. https://doi.org/10.1016/j.jmig.2006.08.009.

63. Zhao J, Tan XJ, Lang JH, Zhao Q. Complications of hysterectomy: analysis of 162 cases. Natl Med J China. 2009;89(41):2931-3. https://doi.org/10. 3760/cma.jissn.0376-2491.2009.41.13.

64 Tozzi R, Malur S, Koehler C, Schneider A. Analysis of morbidity in patients with endometrial cancer: is there a commitment to offer laparoscopy? Gynecol Oncol. 2005;97(1):4. https://doi.org/10.1016/j.ygyno.2004.12.048.

65. Ghazali W, Jamil SA, Sharin IA. Laparoscopic versus Laparotomy Staging Surgery for Endometrial Cancer Malaysia's Early Experience. Gynecol Minim Invasive Ther. 2019;8(1):25. https://doi.org/10.4103/ GMIT.GMIT_25 18.

66 Yip W, Hsiao W. Harnessing the privatisation of China's fragmented health-care delivery. Lancet. 2014;384(9945):805-18. https://doi.org/10. 1016/s0140-6736(14)61120-x.

67. Lawrie TA, Liu H, Lu D, Dowswell T, Song H, Wang L, Shi G. Robot assisted surgery in gynaecology. Cochrane Database Syst Rev. 2019;4(4):CD011422. https://doi.org/10.1002/14651858.CD013422.pub2

68 Xie Y. Cost-effectiveness of robotic surgery in gynecologic oncology. Curr Opin Obstet Gynecol. 2015;27(1):73-6. https://doi.org/10.1097/GCO. 0000000000000134.

69 Paraiso MF. Robotic-assisted laparoscopic surgery for hysterectomy and pelvic organ prolapse repair. Fertil Steril. 2014;102(4):933-8. https://doi. org/10.1016/j.fertnstert.2014.08.010.

\section{Publisher's Note}

Springer Nature remains neutral with regard to jurisdictional claims in published maps and institutional affiliations. 